\title{
DESIGN AND MANUFACTURE OF A FISH PELLET MACHINE WITH A SCREW EXTRUDER METHOD CAPACITY OF BATTER 2.35 TONS/HOUR
}

\author{
N. Nazaruddin ${ }^{1 *}$, Sulaiman ${ }^{1}$ \\ ${ }^{1}$ Jurusan Teknik Mesin, Fakultas Teknik, Universitas Riau \\ *e-mail : nazaruddin@eng.unri.ac.id
}

\begin{abstract}
The design of this fish pellet production machine is based on the working principle of a screw extruder. The working principle of this screw extruder is used for compaction by pushing the dough in the mold which ultimately results in fish pellets in accordance with the size of the mold hole continuously. Screw extruder is made by cutting the steel plate to form a ring. Then the steel plate is spiral formed by heat treatment and then welded to the screw extruder shaft. A binding pellet machine with screw extruder method has been successfully made with components in the form of hopper, screw extruder, screw cylinder, reducer, motor and mold plate. The screw extruder is capable of delivering the dough material at $2.23 \mathrm{~m}^{3} /$ hour with a rotation of $35 \mathrm{rpm}$ with a screw diameter of 6 inch. This fish pellet is driven by an electric motor with $1 \mathrm{HP}$ power. This electric motor will drive the reducer, then turn the screw extruder. This fish pellet production machine has produced a fish pellet production capacity of 2,35 ton/hour
\end{abstract}

Keywords: screw extruder, batter, fish pellet, reducer, axial force

\section{Pendahuluan}

Dengan pesatnya perkembangan budidaya perikanan di Indonesia membuat kebutuhan pakan ikan tersebut menjadi meningkat, sehingga apabila mengandalkan pakan alami saja, tidak akan mencukupi kapasitas ikan tersebut. Untuk itu, banyak petani budidaya ikan banyak menggunakan pakan buatan, sebagai tambahan untuk pakan ikan. Pakan buatan tersebut biasa dikenal oleh petani budidaya ikan dengan nama "pelet". Seiring dengan meningkatnya permintaan pelet di pasar, membuat harga pelet tersebut semakin mahal. Mesin screw extruder produksi pelet ikan ini bisa mengatasi hal tersebut dan dapat dipergunakan oleh pengusaha budidaya perikanan, terutama untuk kalangan masyarakat menengah ke bawah.

Beberapa penelitian yang telah dilakukan di lingkungan Teknik Mesin Universitas Riau untuk Teknologi Tepat Guna diantaranya perancangan dan pembuatan evaporator vakum untuk pengurang kadar air dalam madu [1]-[3], perancangan dan pembuat mesin pencetak bakso kapasitas 250 butir[4]-[8], rancang bangun mesin pencincang pelepah kelapa sawit[9], pelatihan standar higiene dan sanitasi untuk peningkatan ukm pengolahan ikan patin[10] serta kebutuhan daya motor[11]. Oleh sebab itu pada makalah ini dicoba dipaparkan tentang perancangan dan pembuatan mesin pembuat pelet ikan dengan metode screw extruder dengan motor berdaya $1 \mathrm{HP}$.

\section{Studi Literatur}

Pelet adalah bentuk makanan buatan yang terdiri dari beberapa macam bahan yang dicampur dan dijadikan adonan, kemudian kita cetak sehingga bentuknya merupakan batangan kecil-kecil seperti bentuk obat nyamuk bakar. Panjangnya biasanya berkisar antara 1-2 cm. Jadi pelet tidak berupa tepung, tidak berupa butiran dan juga tidak berupa larutan.

Mesin ekstrusi atau biasa disebut extruder[12] merupakan alat yang cukup sederhana namun memiliki keunikan tersendiri. Prinsip dasar kerja alat ini ialah memasukkan bahan-bahan baku yang akan diolah kemudian didorong keluar melalui suatu lubang cetakan (dies) dalam bentuk yang diinginkan. Extruder memiliki banyak jenis ukuran, bentuk dan metode pengoperasian, yaitu:

1. Extruder yang dioperasikan secara hidraulik dimana pada extruder ini piston berperan untuk mendorong adonan melalui lubang pencetak (dies) yang terletak pada ujung extruder.

2. Extruder tipe roda, dimana bahan didorong keluar atas hasil kerja dua roda yang saling berputar.

3. Tipe ulir (screw) dimana putaran ulir akan memompa bahan keluar melalui die.

Alat ekstrusi tipe ulir (screw) terdiri dari 2 jenis utama, yaitu:

a. Extruder berulir tunggal (Single Screw Extruder/SSE)

b. Extruder dengan ulir ganda (Twin Screw Extruder/TSE). 


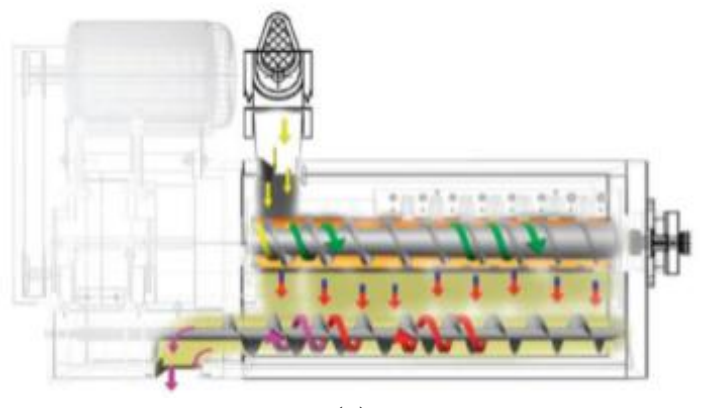

(a)

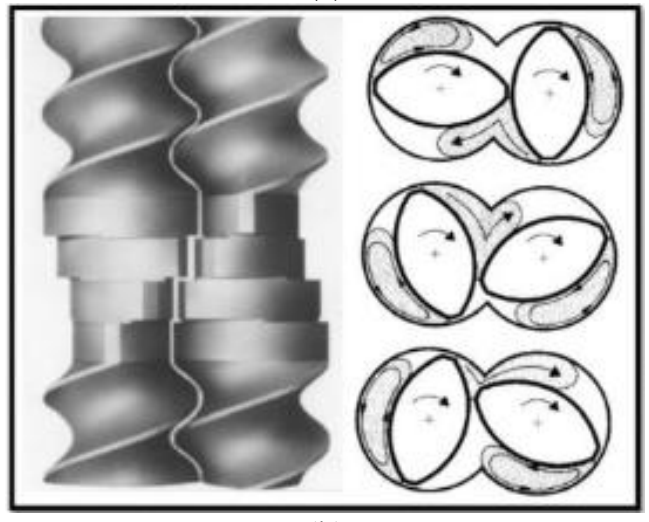

(b)

Gambar 1. Extruder (a) ulir tunggal, (b) ulir ganda

\section{Metodogi Perancangan dan Pembuatan}

3.1 Perencanaan

Perencanaan yang dilakukan didasarkan pada prinsip kerja dari mesin produksi pelet ikan tersebut. Mesin extruder produksi pelet ikan mempunyai prinsip kerja memanfaatkan putaran motor untuk menggerakan screw extruder. Kemudian screw extruder melakukan penekanan (pemadatan) pada adonan yang telah dibuat dan pelet tersebut keluar melalui lubang cetakan yang terpasang pada output mesin ini sendiri. Screw extruder dirancang atau dibuat dengan cara memotong pelat baja membentuk cincin dan dipotong salah satu sisinya. Selanjutnya, pelat baja tersebut dilakukan perlakuan panas, sehingga baja yang berbentuk cincin tersebut melengkung berbentuk spiral. Selanjutnya baja yang berbentuk spiral dilas pada poros yang telah dirancang sebelumnya.

Flow chart perancangan dan pembuatan mengikuti alur seperti Gambar 2.

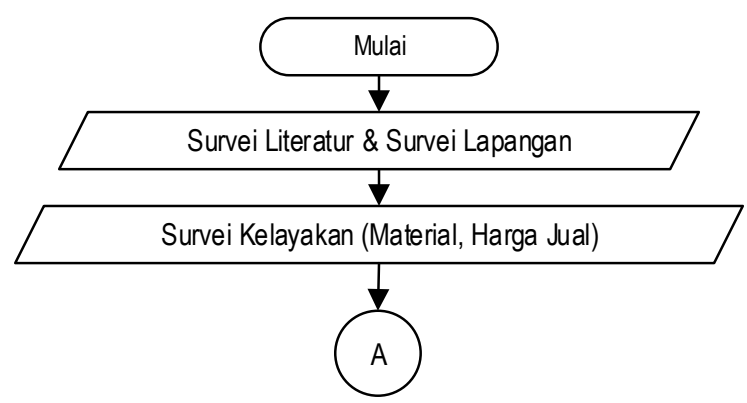

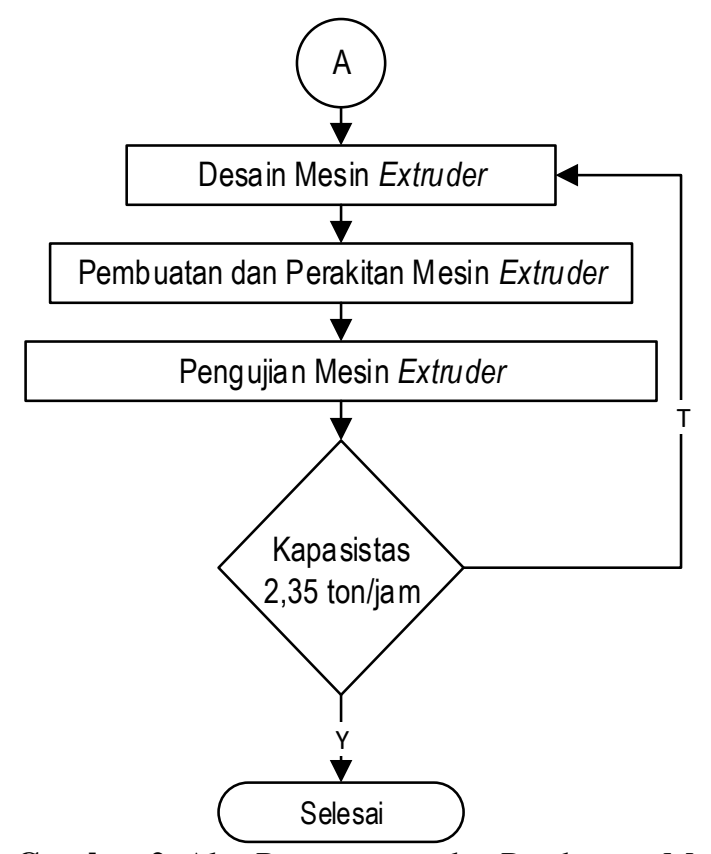

Gambar 2. Alur Perancangan dan Pembuatan Mesin Pelet Ikan

Adapun komponen yang cukup penting dalam perencanaan ini adalah screw extruder. Gambar 3 adalah diagram alir perancangannya.

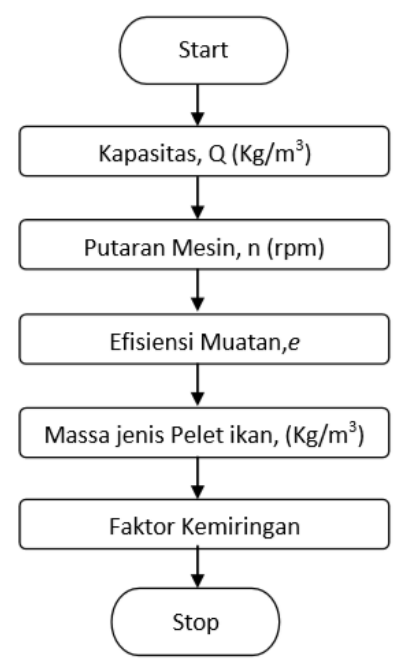

Gambar 3. Flow chart Perancangan Screw Extruder.

Poros utama[13] pada screw extruder ini mengalami gaya dan beban seperti pada Gambar 4 ini.

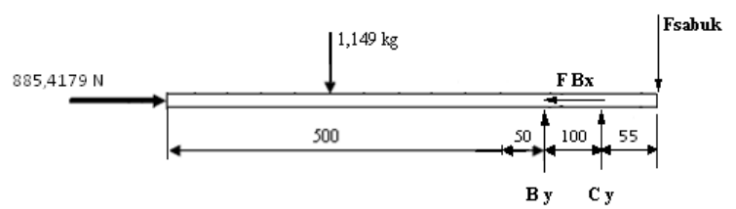

Gambar 4. Diagram Benda Bebas Poros Screw Extruder

Diagram momen lentur yang terjadi sepanjang poros screw extruder yang dihasilkan dari gaya-gaya yang 
bekerja pada Gambar 4, dapat dilihat pada Gambar 5 berikut.

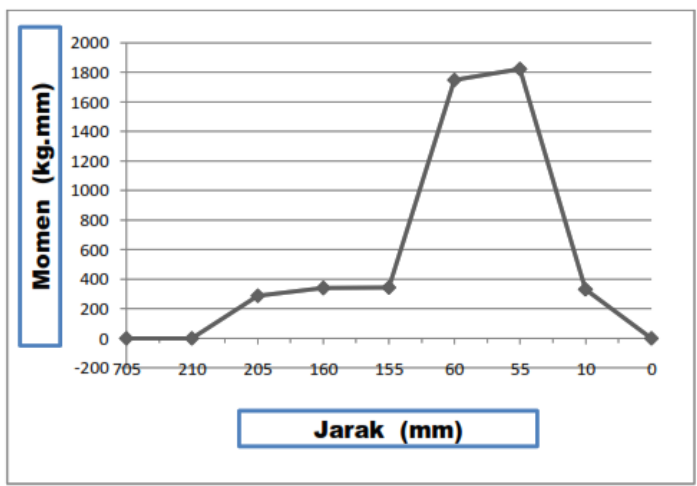

Gambar 5. Diagram Momen Lentur Poros Screw Extruder

Perancangan diameter poros screw didasarkan pada tegangan geser yang akan terjadi dan momen bending yang terjadi pada poros tersebut. Bahan poros yang akan digunakan adalah poros dengan bahan S $45 \mathrm{C}$ dengan kekuatan tarik $58 \mathrm{~kg} / \mathrm{mm}^{2}$ [14]. Momen lentur yang terjadi $(\mathrm{Mb})=1836,7 \mathrm{~kg} \mathrm{~mm}$ (Gambar 5). Faktor koreksi kejut dan lelah untuk momen lentur $(\mathrm{Kt})=2$ Faktor koreksi kejut dan lelah untuk torsi $(\mathrm{Km})=2$. Diameter poros dihitung dari persamaan referensi, menghasilkan diameter poros 30,58 mm,yang dibulatkan menjadi $35 \mathrm{~mm}$ menyesuaikan dengan diameter bantalan (bearing) yang tersedia di pasaran.

3.2 Pembuatan Komponen Mesin Screw Extruder Adapun komponen-komponen yang dibuat adalah
a. Rangka Mesin
b. Screw Extruder Housing
c. Screw Extruder
d. Pelat Cetakan Pelet Ikan
e. Bearing Housing
f. Corong pengarah
g. Wadah penampung pelet ikan

Komponen tersebut dapat dilihat pada Gambar 6 berikut.

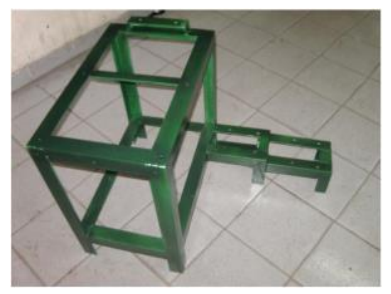

(a)

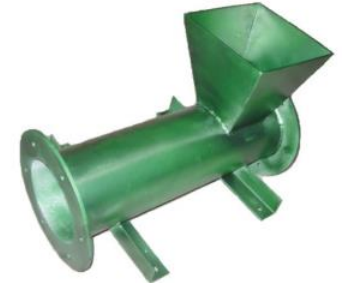

(b)

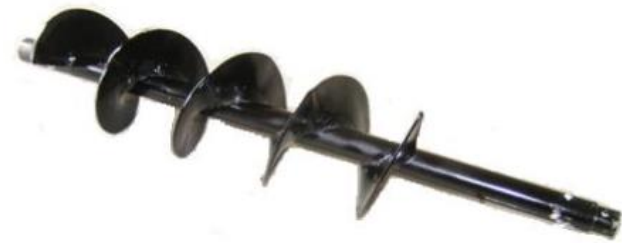

(c)

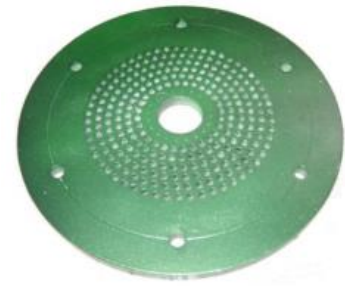

(d)

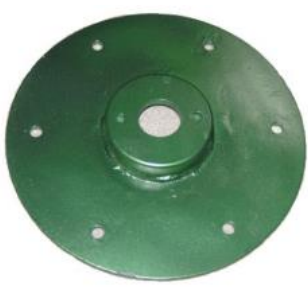

(e)

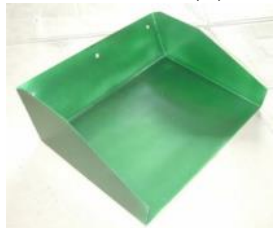

(f)

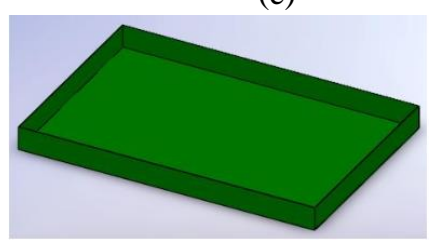

(g)
Gambar 6. Komponen Yang Dibuat Untuk Mesin Screw Extruder

\subsection{Perakitan}

Semua komponen yang telah selesai dibuat selanjutnya digabungkan menjadi satu kesatuan sehingga menjadi suatu alat yang dinamakan mesin screw extruder produksi pelet ikan. Berikut ini diberikan prosedur perakitan mesin screw extruder produksi pelet ikan agar tidak terjadinya kesalahan dalam perakitannya. Prosedur perakitannya adalah sebagai berikut :

1. Silinder mesin screw extruder produksi pelet ikan dipasang pada kerangka.

2. Screw dimasukkan kedalam silinder melalui bagian depan silinder.

3. Kemudian screw dengan silindernya dipasang pada rangka dengan menggunakan baut M10 dan dikunci dengan kuat.

4. Bearing rol kerucut (tapper bearing) dipasang pada poros screw dan ditutup menggunakan house bearing dan dikunci dengan kuat.

5. Bearing radial dipasang pada kedudukannya pada rangka, ujung poros dimasukkan kedalam bearing tersebut.

6. Cetakan pelet ikan dipasang pada bagian depan silinder screw, lubang tengah cetakan tersebut dimasukkan pada poros screw dan dikunci kuat dengan baut M10.

7. Corong pengarah keluar pelet dipasang menggunakan baut M10.

8. Puli 4 inchi dipasang pada poros screw dan dikunci dengan baut M8 dan dikunci dengan torsi yang sesuai.

9. Reducer dipasang pada rangka, pada poros reducer dipasang puli 2 inchi.

10. Motor dipasang pada rangka.

11. Poros motor dan poros input reducer dipasang coupling.

12. Sabuk V dipasang pada puli, dan diatur ketegangan sabuk tersebut dengan menggeser reducer dan motor kebelakang.

13. Setelah posisi sabuk dalam keadaan tegang maka reducer dikunci dengan kuat menggunakan baut M10 pada rangka. 
14. Coupling pada motor di-setting terhadap reducer agar posisi dalam keadaan center atau lurus sehingga tidak terjadi miss-alignment.

15. Mesin siap dioperasikan

\section{Hasil dan Pembahasan}

Telah dilakukan desain dan dibuat sedemikian rupa sehingga mengasilkan bentuk mesin pelet tipe screw extruder seperti Gambar 7.

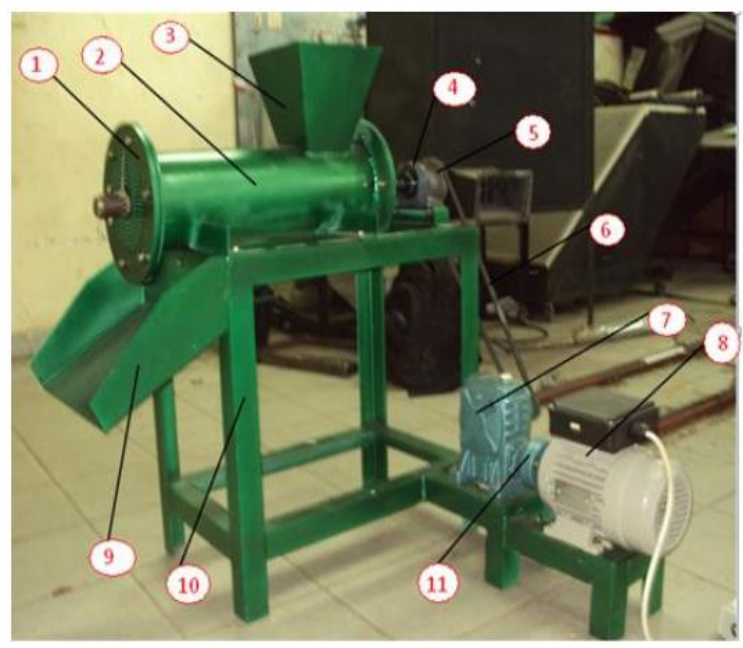

Gambar 7. Mesin Pelet Ikat Tipe Screw Extruder

Keterangan gambar:
1. Kerangka
2. Silinder screw
3 Pelat cetakan
4. Corong
5. Hopper
7. Sabuk
6. Bearing aksial
9. Kopling
8. Reducer
10. Motor
11. Bearing radial
13. Screw extruder
12. Puli 2 inchi

Pada pengujian alat pencetak pelet ikan ini dilakukan sebanyak 3 kali dengan massa adonan yang sama seperti pada Tabel 1 berikut :

Tabel 1. Pengujian Mesin Pelet Tipe Screw Extruder

\begin{tabular}{|c|c|c|c|c|}
\hline Pengujian & $\begin{array}{c}\text { Berat adonan } \\
\text { yang dicetak } \\
\text { (gr) }\end{array}$ & $\begin{array}{c}\text { Waktu } \\
\text { pencetakan }\end{array}$ & $\begin{array}{c}\text { Berat pelet } \\
\text { yang }\end{array}$ & $\begin{array}{c}\text { Berat pelet } \\
\text { yang rusak } \\
\text { (terbentuk (gr) }\end{array}$ \\
\hline I & 1200 & 120 & 890 & 310 \\
\hline II & 1200 & 125 & 900 & 300 \\
\hline III & 1200 & 125 & 910 & 290 \\
\hline Rata-rata & 1200 & 123 & 900 & 300 \\
\hline
\end{tabular}

Bentuk butiran pelet sebelum dan sesudah dapat dilihat pada Gambar 8.

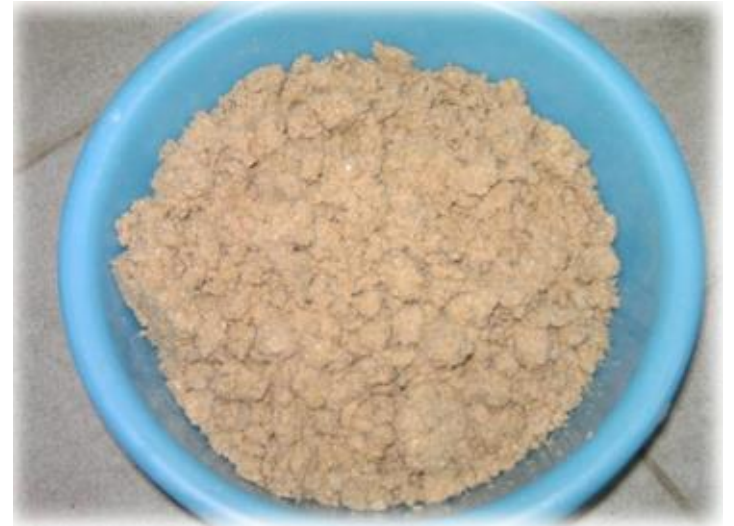

(a)

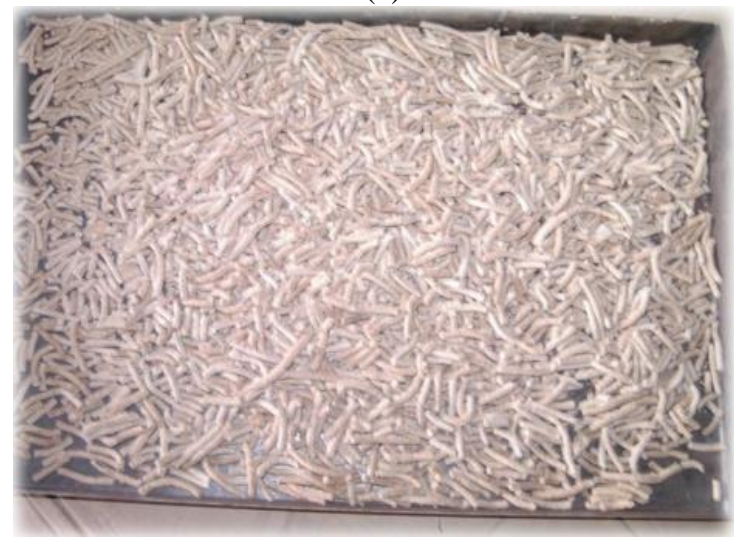

(b)

Gambar 8. Pelet (a) sebelum, (b) sesudah dicetak

Setelah dilakukan pengujian, mesin screw extruder produksi pelet ikan dapat memproduksi $2,35 \mathrm{~m}^{3} / \mathrm{jam}$ adonan pelet. Dimana dalam proses pembuatan pelet tersebut bahan adonan didorong oleh screw ke arah ujung silinder dan menekan plat berlubang sebagai pembentuk pelet.

Pada proses pembentukan pelet terdapat pelet yang rusak ini disebabkan kadar air yang terkandung pada adonan. Dari pengujian dilakukan kadar air sangat berpengaruh pada saat pembentukan pelet. Jika kadar air tinggi maka pelet yang dihasilkan tidak sempurna pada saat keluar dari cetakan karena pelet tersebut terlalu basah sehingga pelet yang satu dengan yang lain saling bergabung atau lengket. Adonan yang kadar airnya terlalu tinggi akan menempel pada screw sehingga hasil pelet yang dihasilkan sedikit. Jika kadar air terlalu rendah maka

batang poros tidak mampu untuk memutar screw, karena kepadatan bahan yang masuk lama kelamaan semakin padat dan keras sehingga membuat poros berhenti berputar.

\section{Kesimpulan}

Adapun kesimpulan yang dapat diambil dari hasil perancangan dan pembuatan mesin pelet ikan ini adalah : 
a. Telah berhasil dibuat sebuah mesin pelet ikat dengan metode screw extruder dengan komponen-kompone berupa hopper, screw extruder, silinder screw, reducer, motor dan pelat cetakan.

b. Screw extruder mampu mengantarkan bahan adonan sebesar $2,23 \mathrm{~m}^{3} / \mathrm{jam}$ dengan putaran $35 \mathrm{rpm}$ dengan diameter screw 6 inch.

c. Diameter poros screw sebesar $35 \mathrm{~mm}$ berbahan S45C dengan beban aksial $885 \mathrm{~N}$ berupa gaya tekan adonan dan gaya dari tegangan sabuk $323 \mathrm{~N}$.

d. Berdasarkan hasil dari pengujian yang dilakukan pada mesin screw extruder produksi pelet ikan ini kapasitas produksi pelet ikan $27 \mathrm{~kg} / \mathrm{jam}$.

e. Pada mesin pelet ikan ini ukuran lubang cetakan bisa diganti sesuai dengan ukuran pelet yang diinginkan.

\section{Daftar Pustaka}

[1] N. Nazaruddin, H. Hapsoh, and A. Afrian, "Perancangan Vacuum Evaporator Penurun Kadar Air Dalam Madu Kapasitas 50 Liter," 2015.

[2] A. I. Darmawan and N. Nazaruddin, "Kaji Pembuatan Sistem Kontrol Mesin Vacuum Evaporator Penurun Kadar Air Madu Kapasitas 50 Liter," J. Online Mhs. Fak. Tek. Univ. Riau, vol. 2, no. 2, pp. 1-6.

[3] A. Afrian and N. Nazaruddin, "Perancangan Ulang Vacuum Evaporator untuk Pengering Madu Kapasitas 50 Liter," J. Online Mhs.

Fak. Tek. Univ. Riau, vol. 2, no. 2, pp. 1-6.

[4] Mikha Febrian; Herisiswanto Herisiswanto; Nazaruddin Nazaruddin;, "Pengembangan Mesin Bakso Dengan Metode Dfma (Design For Manufacturing And Assembly)," J. Online Mhs. Fak. Tek. Univ. Riau, vol. 6, 2019.

[5] J. Nazaruddin,Nazaruddin;Dedi Rosa Putra, Cupu;Aristo, "Perancangan Dan Pembuatan Komponen Mesin Pembuat Bakso Menggunakan Screw Conveyor Dengan Pemotongan Bakso Secara Mekanik," J. Online Mhs. Fak. Tek. Univ. Riau, vol. 6, 2019.

[6] Y. Nazaruddin,Nazaruddin;Dedi Rosa Putra, Cupu; Yefrizal, "Perancangan Sistem Transmisi Mesin Pencetak Bakso Kapasitas 250 Butir/Menit," J. Online Mhs. Fak. Tek. Univ. Riau, vol. 6, 2019.

[7] J. Nazaruddin,Nazaruddin;Jefriadi, "Rancang Bangun Rangka Pencetak Bakso Dengan Kapasitas 250 Butir/Menit," J. Online Mhs. Fak. Tek. Univ. Riau, vol. 6, 2019.

[8] L.

Nazaruddin,Nazaruddin;Romy,Romy;Pangar ibuan, "Perancangan Wadah Perebusan
Bakso Ikan Dengan Daya $1000 \mathrm{~W}$, , J. Online Mhs. Fak. Tek. Univ. Riau, vol. 5, 2019.

[9] S. T. Nazaruddin, "Rancang Bangun Mesin Pencincang Pelepah Kelapa Sawit." Fakultas Teknik Universitas Riau, 2008.

[10] R. Elvyra, D. I. Roslim, and N. Nazaruddin, "PELATIHAN STANDAR HIGIENE DAN SANITASI UNTUK PENINGKATAN PEMBERDAYAAN UKM OLAHAN IKAN PATIN," J. Pengabdi. UntukMu NegeRI, vol. 2, no. 2, pp. 49-54, 2018.

[11] G. Heryana, B. D. Aprianto, D. I. Malik, and A. P. Prakoso, "ANALISA KEBUTUHAN DAYA MOTOR HIDROLIK PADA CAPSTAN BERKAPASITAS 3 TON," $J$. Ilm. Trendtech, vol. 3, no. 1, pp. 30-37, 2018.

[12] N. Frame and J. M. Harper, The technology of extrusion cooking. Springer, 1994.

[13] G. Niemann, "Machine elements design and calculation in mechanical engineering. vol. 1 , fundamentals, connections, bearings, shafts and accessories."

[14] Sularso, Dasar perencanaan dan pemilihan elemen mesin. Association for International Technical Promotion, 1978. 